\title{
MUSICALIZAÇÃO NA EDUCAÇÃO INFANTIL: UM OLHAR SOBRE A BASE NACIONAL COMUM CURRICULAR
}

\author{
Bruna Costa Mariano Ferreguetti Souza
}

DOI: http://dx.doi.org/10.19179/2F2319-0868/2F688

SOUZA, Bruna Costa Mariano Ferreguetti. Musicalização na educação infantil: um olhar sobre a base nacional comum curricular. Revista da FUNDARTE. Montenegro, p.51-64, ano 20, o 40, janeiro/março de 2019.

Disponível em: http://.seer.fundarte.rs.gov.br/index.php/RevistadaFundarte/index> 31 de março de 2020 


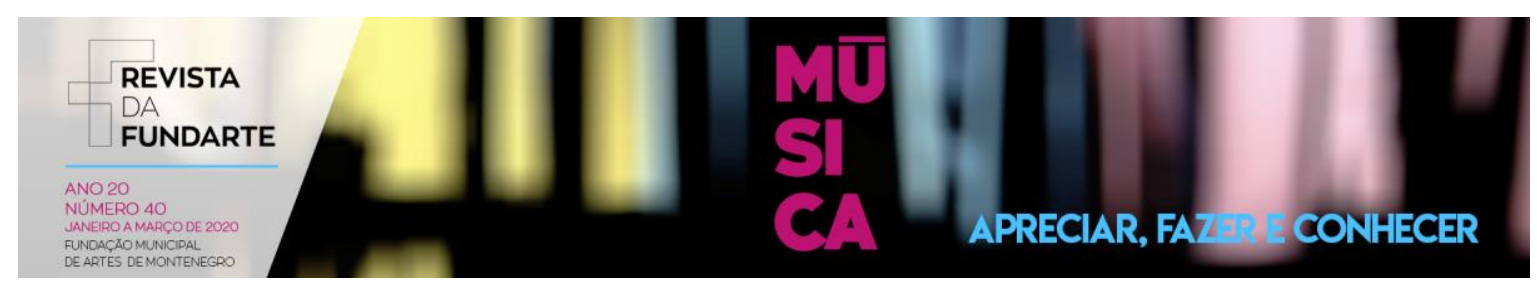

\title{
MUSICALIZAÇÃO NA EDUCAÇÃO INFANTIL: UM OLHAR SOBRE A BASE NACIONAL COMUM CURRICULAR
}

Bruna Costa Mariano Ferreguetti Souza ${ }^{1}$

Resumo: O artigo discute a Música na Educação Infantil a partir das proposições referenciadas na Base Nacional Comum Curricular (2017). Trata-se de uma análise sobre o estabelecimento da Educação Musical como proposta de motivar essa linguagem expressiva das crianças desde a infância. A metodologia científica utilizada se delineou pela pesquisa bibliográfica. Diante desta investigação, depreende-se que a prática da Educação Musical, disposta no currículo da Educação Infantil, antes deve servir de proposta para a formação musical do professor, a fim de contribuir e oportunizar a atividade intencional musical na infância.

Palavras-chave: Educação Infantil; Base Nacional Comum Curricular; Educação Musical.

\section{MUSICALIZACIÓN EN LA EDUCACION INFANTIL TEMPRANA: UNA MIRA EN LA BASE DE CURRÍCULO NACIONAL COMUNIAL}

\begin{abstract}
The article discusses Music in Early Childhood Education based on the propositions referenced in the National Curricular Common Base (2017). This is an analysis about the establishment of Music Education as a proposal to motivate this expressive language of children from childhood. The scientific methodology used was delineated by the bibliographical research. In the light of this research, it can be seen that the practice of Music Education, which is available in the curriculum of Early Childhood Education, should serve as a proposal for the musical formation of the teacher in order to contribute to and facilitate the intentional musical activity in childhood.
\end{abstract}

Keywords: Early Childhood Education; National Common Curricular Base; Musical education.

\section{Introdução}

A íntima relação entre Música e Criança precede os conceitos sistematizados da sociedade, pois desde o ventre materno a interação com os sons, o silêncio, os ritmos fazem parte da vivência dos pequenos. Assim, promover a Educação Musical na Educação Infantil (crianças de 0 a 5 anos) é possibilitar a construção da linguagem sonoro-musical como expressão da infância.

\footnotetext{
1 Professora Efetiva do Colégio de Aplicação (CAp/UFRR). Mestranda em Educação pela Universidade Estadual de Roraima (UERR/IFRR). Especialista em Psicopedagogia Institucional (FESL) e em Docência no Ensino Superior (FESL). Graduada em Pedagogia pela Universidade Federal de Roraima (UFRR). Integrante do Grupo de Pesquisa do Núcleo Criança, Educação e Arte (CrEAr/UFRR), Linha de Pesquisa: Formação de Professores de Educação Infantil. Interessa-se pelos seguintes temas: educação infantil; ensino fundamental; desenvolvimento infantil; artes; formação de professores; musicalização, educação musical.
}

SOUZA, Bruna Costa Mariano Ferreguetti. Musicalização na educação infantil: um olhar sobre a base nacional comum curricular. Revista da FUNDARTE. Montenegro, p.51-64, ano 20, ํo 40, janeiro/março de 2019.

Disponível em: http://.seer.fundarte.rs.gov.br/index.php/RevistadaFundarte/index> 31 de março de 2020 


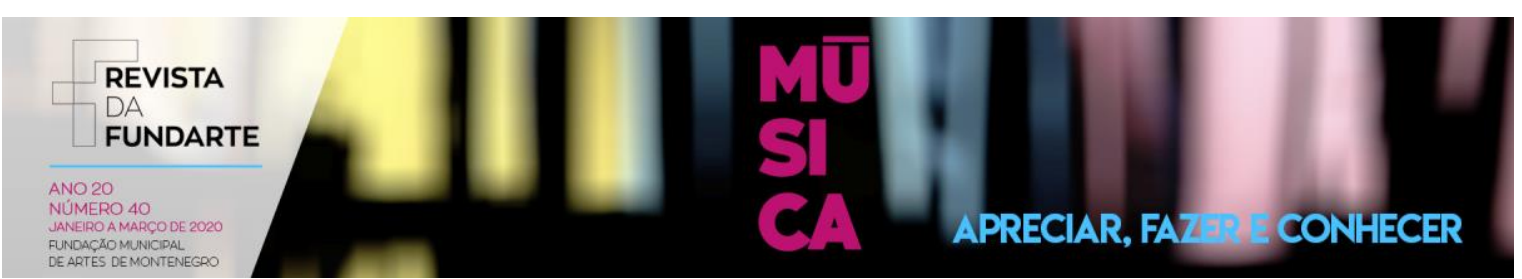

Este artigo propõe uma análise da Base Nacional Comum Curricular (BNCC), na parte específica que aborda a Educação Infantil. Para tanto, dispõe-se inicialmente a concepção de criança e infância como sujeitos históricos e sociais.

Em seguida, apresenta-se um breve histórico acerca do estabelecimento da Educação Infantil como direito das crianças e, ainda, os documentos legais que versam sobre esta etapa da Educação Básica. Estas primeiras compreensões são necessárias para a reflexão sobre a presença da Música na Educação Infantil, evidenciada na BNCC.

Sendo assim, pergunta-se: A Música na BNCC para a Educação Infantil representa uma forma de enriquecer esta linguagem expressiva da criança? Nesse sentido, quais as ações essenciais para promover a musicalização na infância?

Para a elaboração deste trabalho, utilizou-se a pesquisa qualitativa. Segundo Chizzotti (2008, p. 20): “A pesquisa científica caracteriza-se pelo esforço sistemático de - usando critérios claros, explícitos e estruturados, com teoria, método e linguagem adequada - explicar ou compreender os dados encontrados [...]." A metodologia científica escolhida se delineou pela pesquisa bibliográfica. Acerca do instrumento, buscou-se nas referências teóricas (livros, teses, artigos etc.), um embasamento para a temática proposta no presente texto. De acordo com os autores Lakatos e Marconi (2003, p. 183): “[...], a pesquisa bibliográfica não é mera repetição do que já foi dito ou escrito sobre certo assunto, mas propicia o exame de um tema sob novo enfoque ou abordagem, chegando a conclusões inovadoras".

O objetivo principal é discutir sobre a proposta de Educação Musical atualizada na BNCC para as crianças de 0 a 5 anos, alvos da Educação Infantil. Sendo assim, cabe aos educadores ponderar quais as mudanças e adequações imprescindíveis para que se efetive na prática pedagógica o que está disposto como orientação curricular acerca do processo de musicalização na infância.

\section{Um Breve Histórico Sobre A Educação Infantil...}

Para dar início ao debate referente às concepções de criança e infância que norteará a compreensão desse sujeito no texto, faço valer as palavras de Kramer (1999) que define o Ser Criança da seguinte maneira:

SOUZA, Bruna Costa Mariano Ferreguetti. Musicalização na educação infantil: um olhar sobre a base nacional comum curricular. Revista da FUNDARTE. Montenegro, p.51-64, ano 20, no 40, janeiro/março de 2019.

Disponível em: http://.seer.fundarte.rs.gov.br/index.php/RevistadaFundarte/index> 31 de março de 2020 


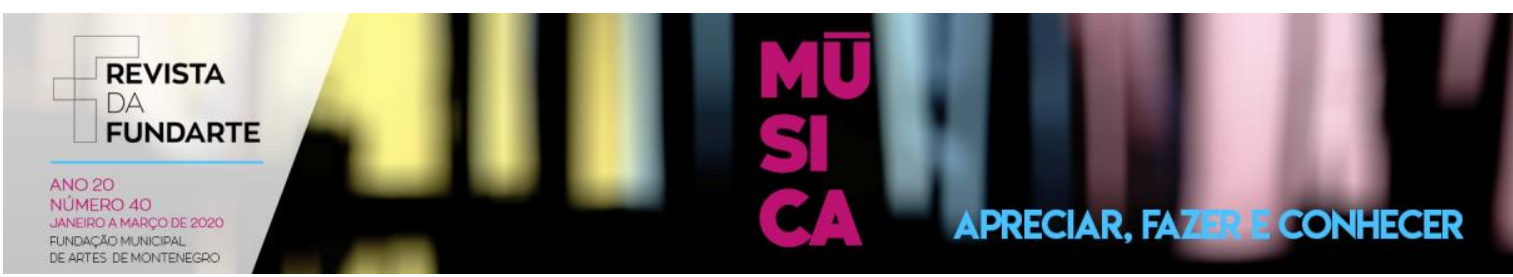

As crianças são sujeitos sociais e históricos, marcados pelas contradições da sociedade em que vivemos. A criança não é filhote do homem, ser em maturação biológica; ela não se resume a ser alguém que não é, mas que se tornará (adulto, no dia em que deixar de ser criança!). Contra essa percepção, que é infantilizadora do ser humano, tenho defendido uma concepção que reconhece o que é específico da infância - seu poder de imaginação, fantasia, criação -, mas entende as crianças como cidadãs, pessoas que produzem cultura e são nela produzidas, que possuem um olhar crítico que vira pelo avesso a ordem das coisas, subvertendo essa ordem. Esse modo de ver as crianças pode ensinar não só a compreender as crianças, mas também a ver o mundo do ponto de vista da criança. Pode nos ajudar a aprender com elas. (KRAMER, 1999, p. 272, grifo nosso).

A criança como sujeito que cria, produz, aprende, desenvolve, expressa, manifesta, entre diversas outras coisas possibilitadas pela simples e complexa condição de ser humano que é, ou seja, sujeito histórico e social, faz parte do imaginário e da realidade a qual contemplamos e buscamos evidenciar por meios de práticas pedagógicas que motivem as experiências e vivências que devem ser propiciadas desde a infância, sobretudo no contexto da Educação Infantil.

Antes de continuarmos, vale lembrar que a criança nem sempre foi enxergada e compreendida assim. A história e o reconhecimento das crianças perpassam por diferentes caminhos e momentos na trajetória da vida humana. Até o período da Idade Média não se percebia a criança de maneira especifica, pelo contrário, era vista apenas como um "adulto em miniatura".

Maia (2012) versa que COMENIUS (1592-1670), o Pai da Didática Magna, foi o primeiro a reconhecer os sentimentos infantis e a considerar uma educação de tudo para todos, inclusive, para as crianças pequenas. A autora expõe que:

[...] para Comenius a infância não representa um objeto a ser teorizado; ela existe porque é necessariamente um ponto de partida. A infância precisa ser educada em sua totalidade. [...] para Comenius, a infância é um elemento constante, e a criança possui toda a potencialidade para aprender em uma ordem e racionalidade, percorrendo, assim, o processo de seu amadurecimento [...]. (MAIA, 2012, p. 20).

Esses estudos a priori acerca de infância, resultaram em novas compreensões sobre a educação das crianças pequenas. ROSSEAU (1712-1778) contribui também de maneira significativa possibilitando um novo olhar sobre a criança e suas peculiaridades, valorizando esta etapa da vida - a infância - como sendo importante no processo de formação humana. Para ele, "[...] a educação na

SOUZA, Bruna Costa Mariano Ferreguetti. Musicalização na educação infantil: um olhar sobre a base nacional comum curricular. Revista da FUNDARTE. Montenegro, p.51-64, ano 20, o 40, janeiro/março de 2019.

Disponível em: http://.seer.fundarte.rs.gov.br/index.php/RevistadaFundarte/index> 31 de março de 2020 
infância não deveria reprimir, modelar ou instruir, mas sim, permitir que a natureza se desenvolvesse na criança”. (DUARTE, 2010, p. 26).

Outros importantes teóricos que se dedicaram à educação das crianças pequenas, considerando a infância uma etapa fundamental para a formação do homem, foram: Pestalozzi e Froebel.

PESTALOZZI (1746-1827) interessava-se pela educação das classes populares, principalmente, das crianças abandonadas e órfãs. $O$ educador "acreditava que a educação deveria partir do conhecimento do aluno, partindo do mais simples para o mais complexo, do conhecido para o desconhecido, do concreto para o abstrato" (DUARTE, 2010, p. 27). Esses ideais estão ainda estão presentes na educação contemporânea.

FROEBEL (1782-1852) foi o criador do kindergarten (jardim de infância), "[...] que priorizava o desenvolvimento global das crianças. O seu objetivo principal era fazer florescer as potencialidades consideradas naturais do indivíduo" (MAIA, 2012, p. 21). Suas concepções de ensino influenciaram a Educação Infantil em vários países, inclusive, no Brasil, uma vez que, em 1875 foi fundado o primeiro jardim de infância particular no Rio de Janeiro (KUHLMANN JR, 2000).

A Educação Infantil, no Brasil, passou por diversas fases. A princípio, a intenção e finalidade de educar as crianças não era objetivo principal, visto que as escolas/creches infantis eram destinadas aos filhos de mães recém inseridas no mercado de trabalho que não tinham com quem deixá-los. Sendo assim, "a discussão referente à consolidação do direito das crianças pequenas à educação em instituições específicas para esse fim vai além das discussões educativas" (CAMPOS; BARBOSA, 2015, p. 354).

O movimento em prol do direito de educação às crianças pequenas teve grande conquista e se consolidou em 1988, com a promulgação da Constituição Federal. A Carta Magna foi o primeiro documento oficial brasileiro a considerar a criança como cidadã, sujeito de direitos, o que configurou grande abertura para o aquecimento das discussões e busca pela efetivação dos direitos da criança, referentes à Educação Infantil.

SOUZA, Bruna Costa Mariano Ferreguetti. Musicalização na educação infantil: um olhar sobre a base nacional comum curricular. Revista da FUNDARTE. Montenegro, p.51-64, ano 20, no 40, janeiro/março de 2019.

Disponível em: http://.seer.fundarte.rs.gov.br/index.php/RevistadaFundarte/index> 31 de março de 2020 


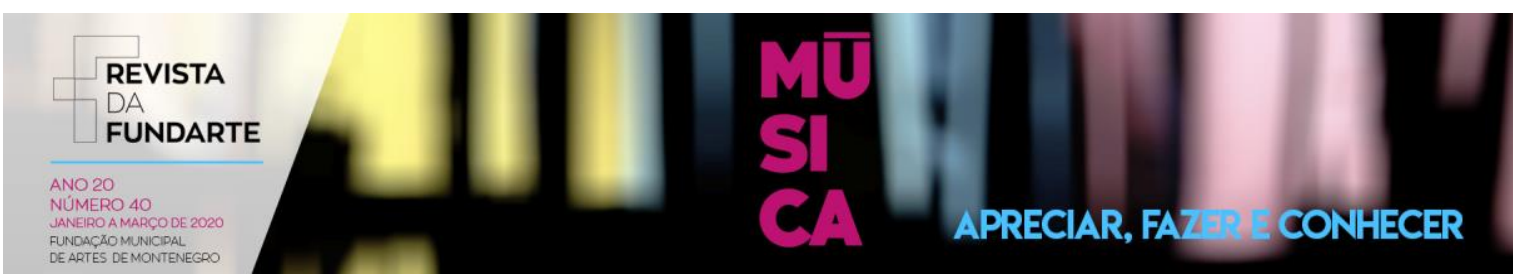

A partir de 1996, com o advento da Lei de Diretrizes e Bases da Educação Nacional (Lei n. 9394), a Educação Infantil passou a fazer parte do Sistema de Ensino Brasileiro, sendo a primeira etapa da Educação Escolar Básica.

Essas conquistas no âmbito legal contribuíram para que fossem observadas políticas que regulamentassem a educação das crianças pequenas. Para atender as determinações expostas na LDB acima citada, foi elaborado pelo Ministério da Educação, em 1998, o Referencial Curricular Nacional para a Educação Infantil (RCNEI). A função deste documento se assegura em:

[...] contribuir com as políticas e programas de educação infantil, socializando informações, discussões e pesquisas, subsidiando o trabalho educativo de técnicos, professores e demais profissionais da educação infantil e apoiando os sistemas de ensino estaduais e municipais. (BRASIL, 1998, p. 13).

A crescente demanda por debates e pesquisas na área da Educação Infantil contribuiu para o aumento na construção de produção científica que visa contribuir e subsidiar na "formulação de orientações e documentos legais que estimulam a melhoria da qualidade da educação oferecida às crianças, assim como os movimentos sociais que atuam na defesa da educação das crianças pequenas" (BARBOSA et al, 2016, p. 12).

Neste contexto de consolidação de políticas para a educação das crianças, outro importante documento consiste na Resolução CNE/CEB no 5, de 17 de dezembro de 2009, que fixou as Diretrizes Curriculares Nacionais para a Educação Infantil (DCNEI). De acordo com Barbosa et al (2016), essas Diretrizes foram:

\begin{abstract}
Elaboradas a partir de ampla escuta a educadores, movimentos sociais, pesquisadores e professores universitários, elas representam o acúmulo de conhecimentos que a área construiu nos últimos anos e destacam a necessidade de estruturar e organizar ações educativas que se orientem por conhecimento consistente acerca do que pode fundamentar um bom trabalho junto às crianças. (BARBOSA et al, 2016, p. 13-14).
\end{abstract}

Presentemente, a discussão acerca de novos fundamentos para a Educação Infantil, sobretudo, o currículo, está envolvida com a implantação da Base Nacional Comum Curricular para a Educação Básica (BNCC). A elaboração deste documento

SOUZA, Bruna Costa Mariano Ferreguetti. Musicalização na educação infantil: um olhar sobre a base nacional comum curricular. Revista da FUNDARTE. Montenegro, p.51-64, ano 20, oㅡ 40, janeiro/março de 2019.

Disponível em: http://.seer.fundarte.rs.gov.br/index.php/RevistadaFundarte/index> 31 de março de 2020 


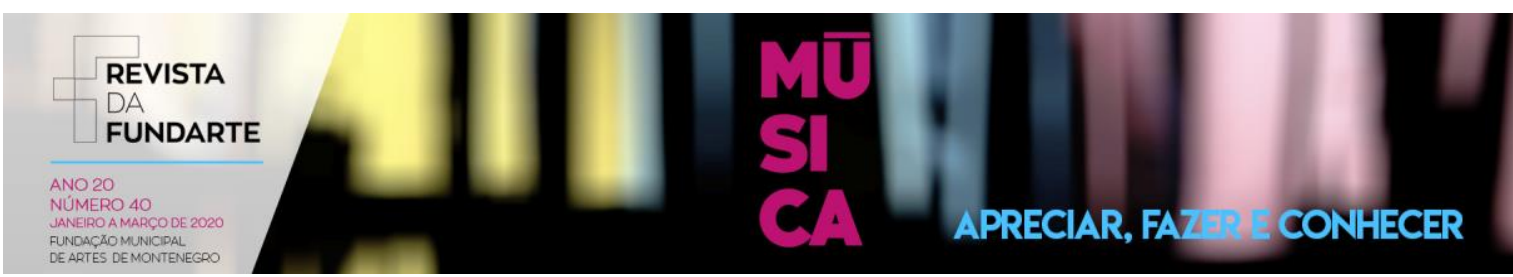

está prevista na Constituição Federal (artigo 210) e também na LDB 9394/96, conforme versa o seguinte texto:

Art. 26. Os currículos da educação infantil, do ensino fundamental e do ensino médio devem ter base nacional comum, a ser complementada, em cada sistema de ensino e em cada estabelecimento escolar, por uma parte diversificada, exigida pelas características regionais e locais da sociedade, da cultura, da economia e dos educandos. (BRASIL, 1996, grifo nosso).

Desse modo, a elaboração de uma Base Nacional Comum, embora tenha encetado questionamentos e dúvidas por parte de estudiosos e pesquisadores da Educação, vale salientar que o documento prevê uma parte diversificada, garantindo assim a diversidade cultural e o respeito as especificidades das infâncias, uma vez que: "[...] a infância é um modo particular e não universal de pensar a criança, considerando-a como um ator social, no sentido de que possa atuar na sociedade recriando-a a todo momento" (DUARTE, 2010, p. 28).

A partir desta breve análise sobre a história da Educação Infantil nos contextos mundial e nacional, e também acerca da trajetória de consolidação legal dessa etapa da Educação Básica no Brasil, convidamos o leitor a refletir sobre a Base Nacional Comum Curricular para a Educação Infantil e quais as possíveis implicações na prática pedagógica com as crianças brasileiras.

\section{A BNCC PARA A EDUCAÇÃO INFANTIL: AVANÇO OU RETROCESSO?}

A Educação Infantil, como direito garantido às crianças enquanto sujeitos históricos e sociais, representa o ponto inicial da vida escolar dos pequenos e precisa ser marcada pela ludicidade oportunizada pelas vivências e experiências desta etapa. Como visto, a necessidade de sistematizar a educação dos pequenos levou à elaboração de documentos oficiais que propuseram definições e diretrizes a fim de promover o trabalho intencional e o desenvolvimento da expressividade das crianças na faixa etária de 0 até 5 anos. Dentre esses documentos, destacam-se as DCNEI e a BNCC.

Acerca disso, Barbosa et al (2016) versa:

As Diretrizes Curriculares Nacionais para a Educação Infantil, assim como a Base Nacional Comum Curricular, são referências importantes, não apenas pelo seu caráter normativo, mas especialmente, por evidenciar um

SOUZA, Bruna Costa Mariano Ferreguetti. Musicalização na educação infantil: um olhar sobre a base nacional comum curricular. Revista da FUNDARTE. Montenegro, p.51-64, ano 20, o 40, janeiro/março de 2019.

Disponível em: http://.seer.fundarte.rs.gov.br/index.php/RevistadaFundarte/index> 31 de março de 2020 


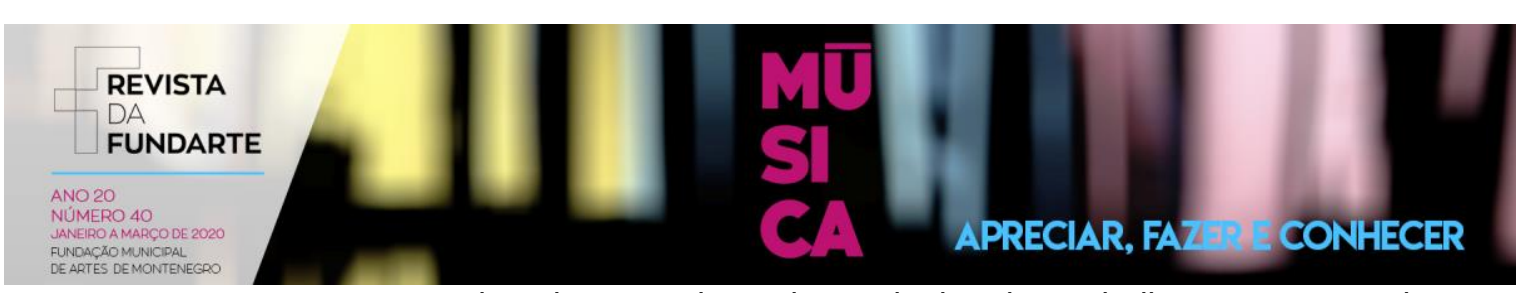

amadurecimento da epistemologia do trabalho com as crianças em instituições educativas. (BARBOSA et al, 2016, p. 18).

A construção da Base Nacional Comum Curricular (BNCC), conforme prevista em legislações anteriores, passou por diversas fases até exposição de sua versão final para a Educação Infantil e Ensino Fundamental. Essa trajetória suscitou debates e reflexões que interferiram, em parte, na elaboração desse documento, homologado em dezembro de 2017. Na proposição dessas discussões, existiu uma preocupação particularizada em: "[...] como lidar com a diversidade social, cultural, étnico-racial, constitutiva das infâncias brasileiras, na medida em que, "comum" nos coloca diante da perspectiva monocultural e padronizada para a educação" (SOUZA, 2016, p. 138).

Considerando as crianças e suas manifestações de infâncias, realmente não há como prever um modelo inflexível a ser seguido, no entanto, a medida em que existe o reconhecimento pelas especificidades, e a organização levando em consideração os diferentes ritmos de aprendizagem, é possível conceber uma sistematização das práticas, de modo a conduzir o aperfeiçoamento da formação docente, sobretudo, para a Educação Infantil.

Existem diversas críticas direcionadas à BNCC, principalmente no tocante ao Ensino Fundamental e Ensino Médio, cabe neste instante discorremos especificamente sobre as propostas da Base para a Educação Infantil, considerando que a BNCC-El representa uma diferente concepção se observada à luz das demais etapas de educação, pois "[...] no que tange à primeira etapa da Educação Básica, evidencia-se a existência de um documento que reconhece a diversidade interna ao próprio Sistema Nacional de Educação" (SOUZA, 2016, p. 143).

A BNCC-El está estruturada a fim de garantir os direitos de aprendizagem e desenvolvimento das crianças, que são: conviver, brincar, participar, explorar, expressar e conhecer-se. A partir desses, o documento estabelece os cinco Campos de Experiências: 1) O eu, o outro e o nós; 2) Corpo, gestos e movimentos; 3) Traços, sons, cores e formas; 4) Escuta, fala, pensamento e imaginação; e 5) Espaços, tempos, quantidades, relações e transformações.

SOUZA, Bruna Costa Mariano Ferreguetti. Musicalização na educação infantil: um olhar sobre a base nacional comum curricular. Revista da FUNDARTE. Montenegro, p.51-64, ano 20, o 40, janeiro/março de 2019.

Disponível em: http://.seer.fundarte.rs.gov.br/index.php/RevistadaFundarte/index> 31 de março de 2020 


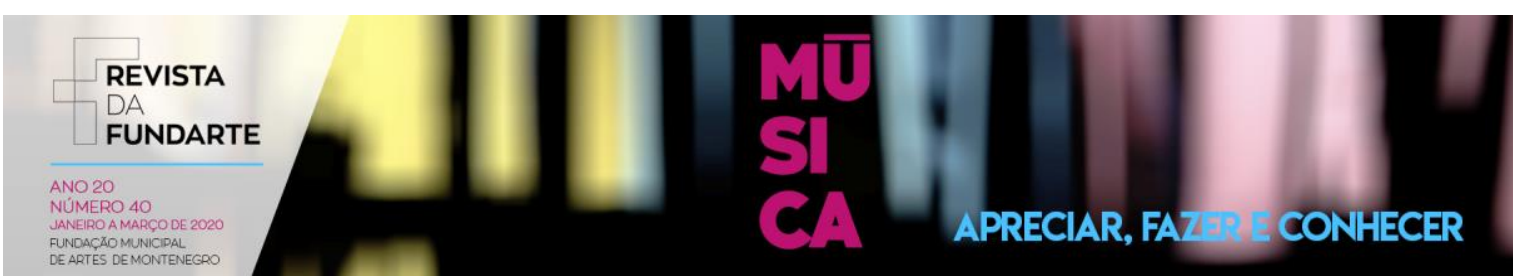

Sobre os Campo de Experiência, Barbosa et al (2016, p. 23) versa que a proposta de arranjo curricular surgiu tendo como base outros países que já utilizam essa organização de currículo, "[...] destacando que a ideia de campos de experiências não deve ser vinculada à de área do conhecimento ou de disciplina escolar [...]", mas aos direitos de aprendizagem e desenvolvimento, que estabelecem a relação constante entre o vínculo educar e cuidar presentes nesta etapa da Educação Básica. Os autores ainda propõem que:

Com isto a BNCEI oferece aos/às professores/as um espectro de objetivos que devem se constituir em uma referência flexível para cada grupamento concreto, considerando importantes diferenças de ritmos, interesses e necessidades entre crianças de uma mesma faixa etária, lembrando a máxima de que o que as crianças têm em comum é que elas são diferentes. (BARBOSA et al, 2016, p. 24).

Vale ressaltar que o ajustamento dos currículos - tanto das instituições e redes de ensino quanto aos cursos de formação de professores - à BNCC deve ser imediato, e sua efetivação precisa ocorrer, de preferência, até 2019 e no máximo, até início do ano letivo de 2020 (BRASIL, 2017). Assim, faz-se necessário rever a prática docente frente às novas orientações, a fim da promoção de múltiplas experiências para as crianças, focando não apenas em aspectos exclusivos e engessados de formação do sujeito, mas a dimensão multidirecional, que constitui o desenvolvimento humano.

A partir dessa análise da BNCC-EI, buscaremos compreender como a Educação Musical está presente neste documento, posto que a Música é linguagem de expressão humana e deve ser oportunizada desde a infância.

\section{A Musicalização na Educação Infantil a partir da BNCC}

Música é linguagem universal humana. A relação entre os sons, os silêncios, a corporeidade, o ritmo, estão presentes nas mais diversas comunidades e povos, evidenciados pelos rituais, festas, brincadeiras. Música é a primeira expressão artística que o ser humano tem contato, pois antes mesmo de nascer, o ambiente sonoro-musical já é vivenciado por meio da fala e cantigas maternas e pelos ricos sons intrauterinos. "Música é forma de expressão, é desenvolvimento estético,

SOUZA, Bruna Costa Mariano Ferreguetti. Musicalização na educação infantil: um olhar sobre a base nacional comum curricular. Revista da FUNDARTE. Montenegro, p.51-64, ano 20, o 40, janeiro/março de 2019.

Disponível em: http://.seer.fundarte.rs.gov.br/index.php/RevistadaFundarte/index> 31 de março de 2020 


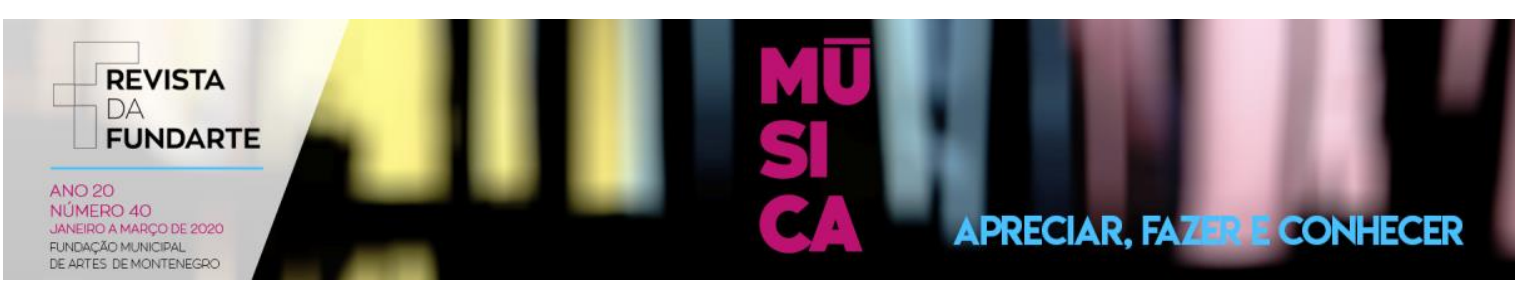

manifestação cultural e, portanto, ter acesso a este conteúdo é tão importante quanto a qualquer outro" (DUARTE, 2010, p. 33).

A presença da Educação Musical, desde a Educação Infantil tem o papel de potencializar a musicalidade das crianças. A musicalização na infância também contribui para o desenvolvimento social, afetivo, cognitivo, psicológico, entre outros aspectos, dos pequenos. No entanto, a Música, em si, atribui enorme significado enquanto expressão humana. Duarte (2010) versa:

A influência da música sobre a vida humana ultrapassa o nível intelectual, pois a música é fruição para o sentimento do homem. Porém, precisa-se tomar cuidado para que o ensino da música não se reduza a um instrumento pedagógico, para desenvolver a criatividade, expressão, etc., mas que tenha importância em si mesma, como assunto, como objeto de estudo por ser ela mesma parte da cultura de todos os povos. (DUARTE, 2010, p. 44).

A Música, enquanto linguagem artística, disposta na BNCC-EI, deve objetivar a expressão infantil - tão singular - no desenvolvimento da linguagem musical, pois as crianças não têm vergonha de cantar, de tocar, mesmo sem conhecer previamente os elementos formais musicais.

Kuhlmann Jr (2010, p. 141) propõe que a expressão por meio da arte, vivenciada desde a infância, é uma disposição própria dos seres humanos e deve ser cultivada desde o início da vida. "Assim, o homem adulto pode muitas vezes não chegar a ser um artista, mas poderá apreciar e contemplar a obra dos demais". Da mesma forma, a musicalização na Educação Infantil contribui para a fruição da expressão sonoro-musical, logo, o homem adulto pode não chegar a ser um instrumentista, cantor ou compositor, mas poderá certamente apreciar e contemplar as sutilezas da Música.

Duarte (2010, p. 30) versa que: "No processo de construção do conhecimento, a criança utiliza-se das mais diferentes linguagens e exerce a capacidade que possui de ter ideias originais sobre aquilo que busca desvendar". $\mathrm{Na}$ BNCC-EI, a Educação Musical está presente nas diversas experiências desde o início e perpassa por toda a Educação Infantil, sobretudo, pela íntima relação que a Música tem com as Brincadeiras.

SOUZA, Bruna Costa Mariano Ferreguetti. Musicalização na educação infantil: um olhar sobre a base nacional comum curricular. Revista da FUNDARTE. Montenegro, p.51-64, ano 20, no 40, janeiro/março de 2019.

Disponível em: http://.seer.fundarte.rs.gov.br/index.php/RevistadaFundarte/index> 31 de março de 2020 


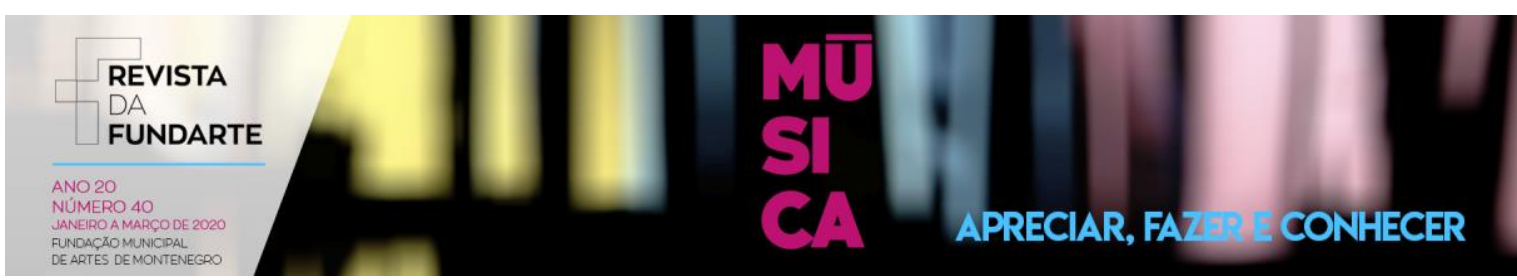

Na BNCC-EI se percebe o propósito da construção da linguagem musical da criança, em particular, no Campo de Experiência chamado "Traços, sons, cores e formas". Nessa categoria, dividem-se os objetivos de aprendizagem e desenvolvimento a partir de grupos de faixa-etárias: bebês ( 0 a 1 ano e 6 meses); crianças bem pequenas ( 1 ano e 7 meses a 3 anos e 11 meses); e crianças pequenas (4 anos a 5 anos e 11 meses).

A iniciação do bebê em um ambiente musical é de suma importância para a apropriação da Música enquanto linguagem expressiva da criança. A graduação do desenvolvimento sonoro-musical possibilita a construção significativa desta linguagem, compreendendo a importância de musicalizar na Educação Infantil. Segundo Piaget (1999, p. 14): "[...] o desenvolvimento mental é uma construção contínua, comparável a edificação de um grande prédio que, à medida que se acrescenta algo, ficará mais sólido".

Nesse contexto, é possível perceber que a BNCC está embasada na teoria Construtivista, visto que possibilita a ação pedagógica dentro de uma construção lógica mental e cognitiva da criança, a fim de se alcançar estágios mais complexos.

Construtivismo significa isto: a idéia de que nada, a rigor, está pronto, acabado, e de que, especificamente, o conhecimento não é dado, em nenhuma instância, como algo terminado. Ele se constitui pela interação do indivíduo com o meio físico e social, com o simbolismo humano, com o mundo das relações sociais; e se constitui por força de sua ação e não por qualquer dotação prévia, na bagagem hereditária ou no meio, de tal modo que podemos afirmar que antes da ação não há psiquismo nem consciência e, muito menos, pensamento. (BECKER, 1993, p. 88 apud LEÃO, 1999, p. 195).

Desse modo, promover a Educação Musical como o intuito de motivar a linguagem musical das crianças é fundamental para desmascarar e superar o senso comum que prega o entendimento de que o "dom" para a Música é algo inato, dado, genético. "A educação musical na infância permite que a criança exerça sua ação espontânea sobre o som, possibilitando interações mais significativas entre elas e os objetos musicais." (DUARTE, 2010, p. 32).

A Educação Musical na Educação Infantil apresenta caráter particular, uma vez que as crianças pequenas estão abertas para o processo de musicalização que ocorre dentro das vivências lúdicas desta etapa. Acerca disso, Brito (2012) expõe:

SOUZA, Bruna Costa Mariano Ferreguetti. Musicalização na educação infantil: um olhar sobre a base nacional comum curricular. Revista da FUNDARTE. Montenegro, p.51-64, ano 20, ํo 40, janeiro/março de 2019.

Disponível em: http://.seer.fundarte.rs.gov.br/index.php/RevistadaFundarte/index> 31 de março de 2020 


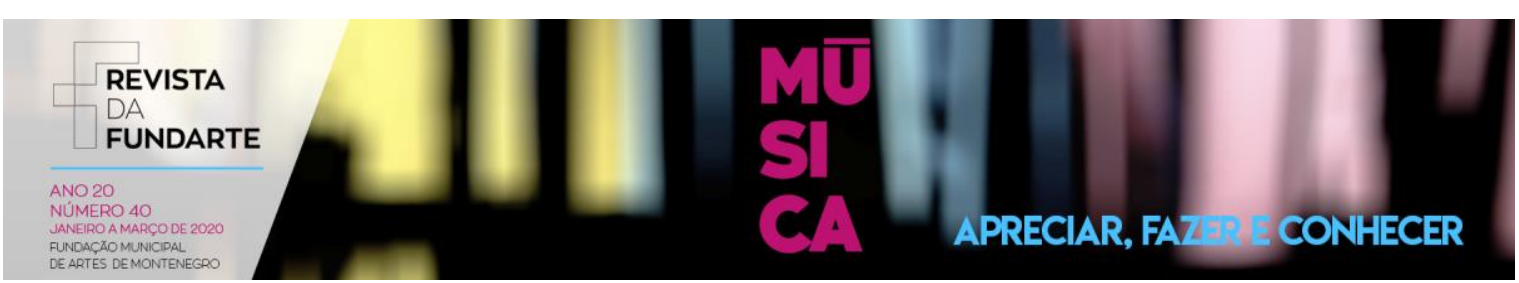

Durante o processo de alfabetização, e daí por diante, a música tende a ser percebida de outra maneira pelas crianças. A vida escolar, com a sistematização do aprender, transforma 0 modo de reconhecer e contextualizar a atividade musical, sendo que um dos pontos a destacar diz respeito à conscientização do fato de que é preciso aprender o que não sabem. Diferença fundamental com relação às crianças menores, que se sentem inteiras e integradas aos seus modos de produzir música. Elas exploram os instrumentos que têm à mão, considerando que já sabem tocá-los, inventam canções, brincam, dançam e, no curso do desenvolvimento, passam a considerar que precisam aprender, inclusive porque já se separam mais dos objetos: eu (sujeito) quero aprender a tocar flauta (objeto), como exemplo. (BRITO, 2012, p. 70, grifo nosso).

Logo, a Musicalização na Educação Infantil precisa considerar a ludicidade, a brincadeira, o faz-de-conta. Para tanto, o(a) professor(a) não deve minimizar a Música como uma ferramenta pedagógica, mas precisa compreender a grandeza de conduzir a formação musical dos pequenos.

A importância da BNCC-EI, enquanto documento que norteará os currículos para a Educação Infantil, representa um grande avanço, pois será necessário a reformulação da formação docente em um contexto de musicalização, uma vez que na Base Comum:

[...] a abordagem da música como linguagem artística específica evita uma concepção conteudista (carregada de longa tradição escolar) para apontar ao desenvolvimento de saberes que permitam a construção autônoma da musicalidade dos estudantes. (ROMANELLI, 2016, p. 481).

Nesse sentido, pensar a Educação Musical das crianças é, antes de tudo, promover a formação musical dos professores que atuarão nesta etapa da Educação Básica.

\section{Considerações Finais}

Diante das indagações feitas com relação a presença da Música no currículo da Educação Infantil, depreende-se que na BNCC-EI há a preocupação com as propostas de musicalização, a fim de enriquecer as vivências e experiências musicais dos pequenos.

SOUZA, Bruna Costa Mariano Ferreguetti. Musicalização na educação infantil: um olhar sobre a base nacional comum curricular. Revista da FUNDARTE. Montenegro, p.51-64, ano 20, o 40, janeiro/março de 2019.

Disponível em: http://.seer.fundarte.rs.gov.br/index.php/RevistadaFundarte/index> 31 de março de 2020 


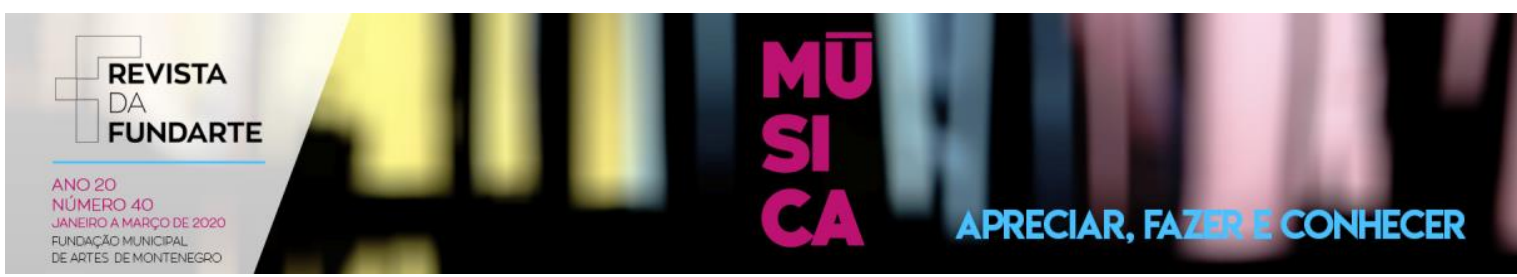

A partir dessa nova forma de pensar e organizar o currículo será possível que as práticas musicais se efetivem, de forma a motivar a linguagem expressiva da criança, no entanto, essa obrigatoriedade precisa estar associada ao o preparo e ao aperfeiçoamento dos professores de Educação Infantil, para promoverem a musicalização no contexto de sala de aula.

É essencial que os docentes que atuam nesta etapa da Educação Básica se apropriem dos conhecimentos musicais e reconheçam a Música como linguagem universal humana. Nesse sentido, é imprescindível que haja a formação da musicalidade dos professores que estão em processo de formação inicial, e também daqueles que necessitam de formação continuada, a fim de refletirem os processos de musicalização das crianças.

Destarte, considera-se que a BNCC-El veio contribuir com a formação docente em um contexto de musicalização, bem como a construção constante da linguagem expressiva musical das crianças pequenas ( 0 a 5 anos). Para 0 aprofundamento deste debate cabe uma futura investigação se esse incentivo de promover a musicalidade continuará nas outras etapas da Educação Básica ou se ocorre uma ruptura deste processo.

Neste momento, quanto a Educação Infantil, consideramos que musicalizar na infância é possibilitar que as crianças se expressem e desenvolvam suas potencialidades em vivenciar, sentir, experimentar as tenuidades da Música.

\section{Referências:}

BARBOSA, M. C. S. et al. O que é básico na Base Nacional Comum Curricular para a Educação Infantil? Debates em Educação. Maceió, v. 8, n. 16, p. 11-28, jul./dez. 2016.

BRASIL. Ministério da Educação. Lei de Diretrizes e Bases da Educação Nacional. Brasília: MEC, 1996.

BRASIL. Ministério da Educação. Secretaria de Educação. Referencial Curricular Nacional para a Educação Infantil. Brasília: MEC / SEF, 1998. v. 1

BRASIL. Ministério da Educação. Conselho Nacional De Educação. Resolução nº 2, de 22 de dezembro de 2017. Brasília: CNE/CP, 2017.

BRITO, Teca A. de. "O menino e a folha de capim": trajetórias do fazer musical da infância. Revista do Centro de Educação, Santa Maria, RS, vol. 37, núm. 1, p. 61-72, 2012.

CAMPOS, Rosânia; BARBOSA, Maria C. S. BNC e educação infantil: quais as SOUZA, Bruna Costa Mariano Ferreguetti. Musicalização na educação infantil: um olhar sobre a base nacional comum curricular. Revista da FUNDARTE. Montenegro, p.51-64, ano 20, ํo 40, janeiro/março de 2019.

Disponível em: http://.seer.fundarte.rs.gov.br/index.php/RevistadaFundarte/index> 31 de março de 2020 


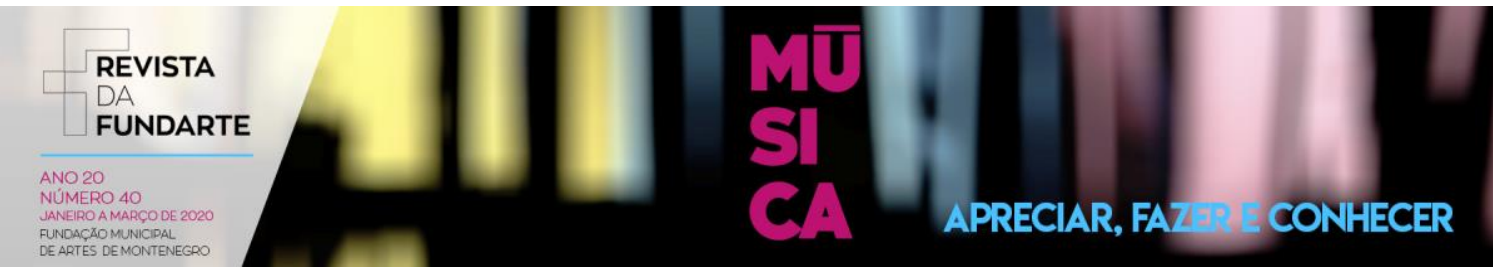

possibilidades? Retratos da Escola. Brasília, v. 9, n. 17, p. 353-366, jul./dez. 2015.

CHIZZOTTI, A. Pesquisa qualitativa em ciências humanas e sociais. 2 ed. Petrópolis, RJ: Vozes, 2008.

DUARTE, R. A construção da musicalidade do professor de educação infantil: um estudo em Roraima. Tese (Doutorado em Educação) - Universidade Federal do Rio Grande do Sul, Porto Alegre, 2010. 213 f.

KRAMER, S. Infância e educação: o necessário caminho de trabalhar contra a barbárie. In: KRAMER, S. et al. (Orgs). Infância e educação infantil. Campinas: Papirus, 1999. p. 269-280.

KUHLMANN JR., M. Educando a Infância Brasileira. In: LOPES, E. M. T.; FARIA FILHO, L. M.; VEIGA, C. G. (Orgs). 500 anos de educação no Brasil. Belo Horizonte: Autêntica, 2000. p. 469-496.

KUHLMANN JR., M. Infância e educação infantil: uma abordagem histórica. Porto Alegre: Mediação, 2010. 5 ed. 192 p.

LAKATOS, E. M. MARCONI, M. de A. Fundamentos de metodologia científica. 5 ed. São Paulo: Atlas, 2003.

LEÃO, Denise M. M. Paradigmas contemporâneos da educação: escola tradicional e escola construtivista. Cadernos de Pesquisa, n. 107, p. 187-206, julho/1999. Disponível em: < http://www.scielo.br/pdf/cp/n107/n107a08.pdf> Acesso em 27 jun 2018.

MAIA, Janaina N. Concepções de criança, infância e educação dos professores de Educação Infantil. Campo Grande, 2012. 135 p. Dissertação (Mestrado) Universidade Católica Dom Bosco.

PIAGET, J. Seis estudos de psicologia. 24 ed. Rio de Janeiro: Forense Universitária, 1999.

ROMANELLI, G. G. B. Falando sobre a arte na Base Nacional Comum Curricular BNCC - um ponto de vista da Educação Musical. Linguagens - Revista de Letras, Artes e Comunicações. Blumenau, v. 10, n. 3, p. 476-490, set./dez. 2016.

SOUZA, Marcia L. A. de. Quais as crianças da Base Nacional Comum Curricular? Um olhar para as "culturas" sem diversidade cultural. Debates em Educação. Maceió, v. 8, n. 16, p. 136-156, jul./dez. 2016.

SOUZA, Bruna Costa Mariano Ferreguetti. Musicalização na educação infantil: um olhar sobre a base nacional comum curricular. Revista da FUNDARTE. Montenegro, p.51-64, ano 20, oㅡ 40, janeiro/março de 2019.

Disponível em: http://.seer.fundarte.rs.gov.br/index.php/RevistadaFundarte/index> 31 de março de 2020 